\title{
A CRÍTICA À OBJETIFICAÇÃO FEMININA EM VOLVER: UM DIÁLOGO ENTRE FILOSOFIA E CINEMA
}

\author{
THE CRITICISM OF FEMALE OBJECTIFICATION IN VOLVER: A DIALOGUE BETWEEN PHILOSOPHY \\ AND CINEMA
}

\author{
Sue Ellen Vieira* \\ Tom Menezes Pedrosa**
}

\begin{abstract}
RESUMO
Este artigo desenvolve uma análise detida do longa-metragem Volver, do cineasta espanhol Pedro Almodóvar, focando em aspectos que retratam a situação da mulher como Outro e sua objetificação. Para isso, serão mobilizados conceitos presentes na obra $O$ segundo sexo, da filósofa existencialista Simone de Beauvoir, os quais servirão de suporte para que se possa realizar um diagnóstico dos mitos opressores que encarceram a mulher em sua imanência. Nesse sentido, serão identificadas e examinadas personagens e cenas pontuais, ao longo da trama, em especial da parte introdutória do filme, quando as mulheres ainda se apresentam como mera condição imagética para a ação dos homens. Como instrumento de interlocução, nessa interface entre filosofia e cinema, será utilizada a noção de conceito-imagem, do filósofo argentino Julio Cabrera, o qual defende que, ao provocar a dimensão afetiva (pathos) do espectador, o cinema desperta sua cognição $(\log o s)$, problematizando questões e chamando o espectador à reflexão sobre assuntos que, no caso em tela, envolvem a condição feminina e sua afirmação como Sujeito, tema caro a Beauvoir.
\end{abstract}

PALAVRAS-CHAVE: Beauvoir; Almodóvar; existencialismo; imanência; objetificação feminina.

\begin{abstract}
This article develops an in-depth analysis of the feature film Volver, by the Spanish filmmaker Pedro Almodóvar, focusing on aspects that portray the situation of women as Other and their objectification. For this, concepts present in the work The second sex, by the existentialist philosopher Simone de Beauvoir, will be mobilized, and will serve as a support for making a diagnosis of the oppressive myths that imprisoned women in their immanence. In this sense, specific characters and scenes will be identified and examined throughout the plot, especially the introductory part of the film, when women still present themselves as mere imagery for the action of men. As a tool for interlocution, in this interlinking between philosophy and cinema, we will use the notion of concept-image by the Argentine philosopher Julio Cabrera who defends that, by provoking the affective dimension (pathos) of the viewer, cinema awakens their cognition (logos), problematizing issues and calling the viewer to reflect on topics that, in the case in question, involve the female condition and his affirmation as a Subject, a theme dear to Beauvoir.
\end{abstract}

KEYWORDS: Beauvoir; Almodóvar; existentialism; immanence; female objectification.

\footnotetext{
* Mestre em filosofia pela Universidade Federal do ABC. Bacharel, licenciada em Filosofia pela Universidade Metodista. E-mail: suesuenhamandu@gmail.com.

** Bacharel em Direito pela Universidade Católica de Pernambuco. Mestrando do Programa de Pós-Graduação em Filosofia da Universidade Federal do ABC. E-mail: tomdireitounicap@yahoo.com.br.
} 


\section{INTRODUÇÃO}

Em O segundo sexo, Simone de Beauvoir reflete sobre a situação de imanência da mulher. Ela utiliza o termo "Outro", ao longo da obra, a fim de diagnosticar a posição subalternizada da mulher na sociedade, bem como em seus próprios padrões de pensamento. Um de seus escopos, ao pôr este projeto em prática, é responder por que a mulher é o Outro.

Nesse âmbito, para um ser se definir, ele deve definir algo em oposição a si. "No momento em que o homem se define como sujeito e liberdade, a ideia de Outro se mediatiza", diz Beauvoir (2016a, p. 115-116). Assim, para cada sujeito, deve haver um objeto. Essa relação recíproca sinaliza o problema fundamental do monopólio masculino da subjetividade.

A partir disso, verifica-se que há um desequilíbrio, nessa concepção, quando aplicada à relação entre homens e mulheres, já que, ao longo da história, o homem ocupou o papel de um, sendo o Sujeito, o absoluto, que vê a mulher como o objeto, o desvio, o inessencial. Desse modo, a mulher tem valor como parceira sexual, mas não como entidade independente.

O princípio masculino é, então, parâmetro para tudo aquilo que é humano, enquanto a mulher é contingente, desviante e não essencial. Ela o completa, mas ela mesma é incompleta. Por ser fundamentalmente antinatural viver no papel de objeto, a mulher hesita entre o papel histórico que lhe é oferecido e uma afirmação de sua liberdade. Para aceitar seu papel de outro absoluto, sem reciprocidade, ela deve negar uma grande parte de sua humanidade e renunciar a todas as reivindicações de liberdade.

Em seu estudo, Beauvoir tenta desmascarar todos os mitos que constroem uma essência feminina, à qual as mulheres veem-se coagidas a se adaptar. Ela esmiúça, em detalhes, o que chama de "eterno feminino", que é aquela "obscura e irredutível essência: a feminilidade" (BEAUVOIR, 2016a, p. 272). Esse mito assume muitas formas - a santidade da mãe, a pureza da virgem, a fecundidade do útero - , mas em todos os casos serve para negar a individualidade das mulheres e prendê-las dentro de ideais irrealizáveis.

É nesse sentido que a análise do filme Volver servirá para que se identifiquem aspectos da teoria de Beauvoir em ação. Destaca-se, portanto, que é essa obra de Pedro Almodóvar o objeto deste estudo, sendo os aportes teóricos beauvoirianos as ferramentas que serão utilizadas para que se possam analisar, no filme, certos fatores que denunciam a opressão feminina, apontada em $O$ segundo sexo, décadas antes. 
Vale ressaltar, no entanto, que serão observadas — sobretudo — as passagens fílmicas iniciais. Isso porque há uma reviravolta no decorrer do filme e, assim como ocorre em quase toda a filmografia almodovariana, as mulheres assumem as rédeas da situação. Este artigo refletirá, portanto, sobre a primeira parte, quando as mulheres ainda são mera pausa contemplativa para a ação dos homens, mas chega também a tangenciar a reação feminina, numa transição para a guinada rumo à transcendência. Ressalta-se, outrossim, que a narrativa de coisificação da mulher é forjada, por Almodóvar, em tom crítico, e não de cumplicidade.

Sendo assim, no intuito de facilitar a leitura do presente texto, faz-se oportuno apresentar — nas linhas que seguem - um epítome da obra cinematográfica que será aqui estudada, porquanto Volver é um filme complexo pelos múltiplos temas que abarca, sendo um mergulho na vida de algumas mulheres: Raimunda, a personagem principal, mora num bairro popular de Madrid, com o companheiro Paco e a filha Paula, de 14 anos. Em um dia de forte ventania, ela retorna ao povoado onde nasceu, com sua irmã Sole, para cuidar do túmulo de seus pais, que morreram três anos antes, em um incêndio. Ela, então, aproveita para visitar a tia Paula, que está velha e doente. Poucos dias depois, Paula, filha de Raimunda, mata, com uma facada, Paco, por este tentar estuprá-la; neste ínterim, Sole telefona para anunciar a morte da tia Paula. Como resultado dessas duas mortes, Raimunda vai, gradualmente, superando o seu passado, o qual vem à luz gradualmente.

Com o propósito de interpretar tal produção fílmica, em sua relação com o existencialismo beauvoiriano, lançar-se-á mão da noção de conceito-imagem, presente em O cinema pensa: uma introdução à filosofia através dos filmes, do filósofo argentino Julio Cabrera. Por meio dessa concepção, a filosofia é interpretada como uma atividade de pensamento lógico-racional, atuando através de conceitos (ou "conceitos-ideia", segundo sua definição). Por outro lado, Cabrera defende que as possibilidades conceituais seriam fortificadas por meio da capacidade eloquente da sétima arte em expressar ideias imagéticas.

Abraça-se, portanto, a ideia de cinema logopático, na qual logos seria a lógica argumentativa e pathos a capacidade de provocar a audiência por meio dos sentidos, num contexto puramente afetivo. Por conseguinte, o autor trabalha conceitos cognitivo-afetivos, utilizando-os como problematizadores da concepção clássica da filosofia sobre os conceitos. 


\title{
1 A MULHER CONFINADA EM SEU SEXO: MERA CONDIÇÃO IMAGÉTICA
}

A ideia de que ser mulher ${ }^{1}$ é o resultado de um devir em movimento implica, para Simone de Beauvoir, que a condição de inferioridade feminina não é natural, mas colocada. Desse modo, a mulher seria alteridade em relação ao Um, porquanto, num momento da evolução histórica, foi escolhida para sê-lo.

$\mathrm{Na}$ linha do pensamento existencialista, a filósofa sustenta que foi no curso da história que a mulher, aprisionada na imanência de um mundo no qual prevalece o princípio da transcendência, tornou-se o Outro. Como afirma o filósofo australiano Jack Reynolds (2014, p. 203):

\begin{abstract}
O primeiro ponto principal a surgir de $O$ Segundo Sexo é a noção da mulher como outro ou, como o título de seu livro sugere, como segundo. Para de Beauvoir, os homens historicamente assumiram a posição de sujeito e as mulheres têm sido designadas como o que é diferente do sujeito; em outras palavras, o homem é a norma e a mulher está fora da norma..
\end{abstract}

Assim, o ser cuja essência é o oposto da consciência é o ser feminino, no qual a mulher, como Outro, torna-se ela mesma. Nessa perspectiva, Beauvoir afirma que a mulher constituiria o Outro absoluto, dependente da aprovação masculina. A mulher seria, assim, considerada como um órgão reprodutor, e não como uma igual na luta pelo reconhecimento. "Pretende-se torná-la objeto, votá-la à imanência, porquanto sua transcendência será perpetuamente transcendida por outra consciência essencial e soberana." (BEAUVOIR, 2016a, p. 26).

Isso fica claro quando Beauvoir acende a ideia de que aceitar a maternidade como um destino, um desígnio do "instinto maternal”, é subjugar-se à espécie dita superior. Nessa direção, a filósofa argumenta:

Na boca do homem o epíteto "fêmea" soa como um insulto; no entanto, ele não se envergonha de sua animalidade, sente-se, ao contrário, orgulhoso se dele dizem: “É

\footnotetext{
${ }^{1}$ Tendo em vista que pautas interseccionais ainda não faziam parte da agenda feminista, na época em que $O$ segundo sexo foi escrito, frisa-se que Simone de Beauvoir (assim como Almodóvar) assina uma obra engendrada a partir de epistemologias brancas e eurocêntricas, apesar de haver resquícios de que ela não parecia estar completamente alheia a questões raciais e de classe, quando afirma, por exemplo, que "burguesas são solidárias dos burgueses e não das mulheres proletárias; brancas, dos homens brancos e não das mulheres negras" (BEAUVOIR, 2016, p. 16). Entretanto, é preciso enfatizar que o conceito de interseccionalidade tornou-se fundamental para a teoria feminista e que ele foi forjado, em 1989, por uma jurista estadunidense: Kimberlé Crenshaw, a qual elaborou uma das mais relevantes contribuições teóricas em torno deste conceito. Em seu artigo - Demarginalizing the intersection of race and sex: a black feminist critique of antidiscrimination doctrine, feminist theory and antiracist politics (1989) - Crenshaw tenta entender por que as mulheres negras têm dificuldade em fazer com que os tribunais reconheçam a discriminação que elas sofrem no trabalho.
} 
um macho!" O termo "fêmea" é pejorativo não porque enraíza a mulher na Natureza, mas porque a confina no seu sexo. (BEAUVOIR, 2016a, p. 31).

Merece destaque, outrossim, a premissa existencialista de que "a existência precede a essência" (SARTRE, 2014, p. 20), já que - indo de encontro a ela - o eterno feminino confere uma essência às mulheres: os mitos da maternidade, da amante, entre outros, constroem um caráter essencial que as mulheres são levadas a assumir. A título de exemplo, vale atentar que, na literatura de cinco escritores analisados por Beauvoir ${ }^{2}$, em $O$ segundo sexo, a filósofa observa — em referência ao retrato de todas as mulheres em seus trabalhos — que "o único destino terrestre que se lhes reserva é sempre o homem" (BEAUVOIR, 2016a, p. 327-328).

Ao contrário, em Volver, longa-metragem de Pedro Almodóvar, o processo de luto pela morte das figuras masculinas tem um significado alegórico de libertação das amarras do sexo oposto: as figuras femininas são ou ficarão viúvas ao longo da narrativa. $\mathrm{O}$ assassinato ou a rejeição dos homens que as cercam fazem renascer, nelas, o Sujeito até então soterrado por uma alteridade não recíproca.

Essa demissão das personagens masculinas da trama representa a forma de as mulheres se encontrarem consigo mesmas, isto é, de existirem e criarem, elas próprias, sua essência. A partir disso, as personagens conduzem todas as situações da vida sem os homens: elas deixam, então, de ser mera condição imagética.

No cinema comercial $^{3}$, de outro modo, a presença feminina adquire uma função formadora do inconsciente patriarcal (MULVEY, 1983, p. 438); em outros termos, dá alicerce ao mundo masculino opressor denunciado por Beauvoir. Essa falta de autonomia e de escolha da existência feminina é expressa por um dos mitos mais antigos: a lenda do Gênese (Adão, formado - do barro - pela vontade de Deus; e Eva, formada da costela de Adão), na qual a narrativa é projetada para mostrar que mesmo o nascimento das mulheres não era autônomo (BEAUVOIR, 2016a, p. 201), sendo, portanto, um destino predeterminado. Nessa lenda, portanto, a mulher não foi forjada com um fim em si: o propósito de sua criação era o de acalmar a solitude de Adão.

\footnotetext{
${ }^{2}$ Destaca-se um elemento que pode parecer secundário, se comparado a outros aspectos cruciais da elaboração teórica de Beauvoir, mas que é absolutamente central: a literatura como traço sintomático e direto do pano de fundo ideológico de uma época e de uma situação.

${ }^{3}$ Sempre que o cinema comercial for mencionado, estar-se-á aludindo a características presentes na maioria desses filmes (em geral, produtos da indústria hollywoodiana). Isso não significa, no entanto, que não exista nenhum filme comercial com uma consciência dos problemas de gênero.
} 
Como já dito, a desigualdade entre homem e mulher, em sua origem, não é natural, mas culturalmente construída, já que, ao nascerem, ambos os sexos se equivalem, física e intelectualmente, de acordo com o existencialismo beauvoiriano. No entanto, o homem, por ser o Sujeito, por ser dominante, por ser absoluto, encerra a mulher em sua alteridade, reduzindo-a a um ser inferior, reprodutor, biológico ${ }^{4}$, um ser relativo. Logo, a mulher não é reconhecida como Sujeito, sendo, por isso, objetificada. O "eterno feminino" é, portanto, "forjado pelo homem por meio da situação que ele impõe à mulher” (KRUKS, 1995, p. 85, tradução nossa).

“Mas antes de mais nada: o que é uma mulher?”, indaga Beauvoir (2016a, p. 9). E, num tom provocativo, ela mesma responde mais adiante: "a mulher? É muito simples, dizem os amadores de fórmulas simples: é uma matriz, um ovário; é uma fêmea, e esta palavra basta para defini-la” (BEAUVOIR, 2016a, p. 31). A filósofa afirma que o simples fato de se fazer essa pergunta denota, desde já, a posição subalternizada das mulheres na sociedade.

A mulher é, por isso, aquela que encena sobremaneira o seu amoldamento às regras (de modo diverso, outros corpos - como o corpo trans - não encontram lugar no simbólico, em virtude de violarem todas as normas e anseios). Dessa forma, ela se faz por inteira imanência, em contínua performatização, abnegando a condição de ser. Ao contrário do homem, que é a norma, ou seja, aquele que é e, por consequência, transcende, a mulher desempenha todos os seus múltiplos ideais-mulher, urdidos socialmente: a meiga, a narcisista, a meretriz, a bemcomportada, a máscula, a "feita para casar", e assim por diante.

Ao se ajustar a esses papéis, que lhe são impostos pelo mundo masculino, a mulher converte-se em um desenho no qual ela se arremessa e é arremessada. Por essa razão, tudo aquilo que se imputa ao universo feminino é ultrajante (ser "maria-vai-com-as-outras", ser “afeminado", ser "mulher da vida"). Já a expressão "mal-amada", por exemplo, insinua que a presença do homem - ou a falta dele - teria o condão de delinear a essência feminina.

Essa pintura burlesca da imagem feminina torna-se notória, outrossim, em mulheres excessivamente sexuadas, no mais emblemático estilo femme fatale, nas quais se travestem dragqueens ou travestis, encenando um ideal de lascívia feminina forjado a partir do apetite masculino. Por outro lado, pode-se destacar outra imagem caricata do universo feminino que é possível ser vista em anúncios de panela e detergente, por exemplo —, como a da dona de casa e a da esposa dedicada, igualmente delineada para o proveito da sociedade machista.

\footnotetext{
4 “Além disso, embora Beauvoir insista que a biologia não é um 'destino', as construções sociais — inscritas no corpo feminino - são centrais na definição da mulher não apenas como outro, mas como um outro inferior.” (KRUKS, 1995, p. 85, tradução nossa).
} 
Tendo em vista o exposto, percebe-se, ao analisar as personagens de Volver, que a relação entre Raimunda - "uma mulher forte, uma perseverante nata, mas muito frágil emocionalmente" (STRAUSS, 2008, p. 311), nas palavras de Almodóvar - e seu marido, Paco, está marcada pelas condições patriarcais. Quando Raimunda e Paula, sua filha, voltam de Madrid, por exemplo, Paco está assistindo a uma partida de futebol e pede — corroborando com o clichê usual - à Raimunda que o traga mais cerveja; além disso, não se dirige a ela de maneira gentil ou afetuosa. Fica claro, então, que as tarefas do lar são uma obrigação da mulher.

Dessa maneira, o espectador, que está familiarizado com a sociedade patriarcal, percebe a violência estrutural sem que Almodóvar precise colocá-la em evidência de modo explícito. Isso porque o cinema incita o foco do pensamento para a análise de alguma questão problemática. De acordo com Julio Cabrera, filósofo argentino, é necessário - para se fazer filosofia com um filme - haver uma espécie de diálogo entre o espectador e os componentes lógicos desse filme, isto é, ter a compreensão de que a imagem em movimento transmite uma ideia ou um conceito (CABRERA, 2006, p. 22). E, no caso de Almodóvar, os elementos cênicos carregam forte simbologia, desde a escolha de cores, que refletem sentimentos de personagens e situações, até objetos que, a princípio, seriam meros acessórios.

Dentro da cozinha, o plano aéreo que Almodóvar escolhe para mostrar Raimunda deixa seu decote claramente visível nesse enfoque, ao lavar uma faca. Isso pode ser interpretado como uma apresentação artisticamente codificada do comportamento de Paco diante de sua mulher: ele só enxerga seu corpo feminino e suas tarefas domésticas.

Em diálogo com a simbologia implícita da cena anterior, Almodóvar mostra — na cena seguinte - a violência estrutural de maneira explícita: Paco assedia Raimunda na cama que dividem, reduzindo-a completamente a um objeto de prazer. Ele vai tão longe que tenta persuadi-la do ato sem sua participação.

Por meio dessa leitura fílmica, percebe-se que a resposta de Beauvoir à pergunta feita por ela mesma - "o que é uma mulher?" - encontra-se, com efeito, amparada no fato de que as mulheres são o Outro, em oposição ao Sujeito masculino. Isto é, a opressão das mulheres surge de sua alteridade, já que lhe foi negado continuamente o acesso a uma existência autônoma como sujeito que se coloca e define, para-si $^{5}$, o que é. Em vez disso, as mulheres são

\footnotetext{
5 "Há dois conceitos fundamentais no existencialismo de origem sartriana e também constantemente utilizados por Beauvoir. A ideia de para-si e em-si. O para-si é o único possível enquanto sujeito e possui uma consciência intencional. Este se abre e doa sentido ao mundo, portanto, é o sujeito que se faz e faz o mundo ao seu redor. Por sua vez, o em-si é o objeto pensado, ele não se faz, mas se fecha em si mesmo, foi pensado por outrem e não tem condições de pensar por si próprio. No para-si existe um sujeito que pensa e sempre que pensa está pensando em
} 
o Outro, elas são aquilo que não é masculino. Elas são definidas por aquilo que não são, e não pelo que são.

\section{O PRINCÍPIO MASCULINO COMO REFERÊNCIA PARA O QUE É HUMANO}

Na continuação do filme, depois da morte de Paco, vê-se de novo Raimunda lavando a mesma faca; desta vez, ela limpa o sangue de Paco. A cena também é filmada de cima. Nenhuma das duas imagens aéreas, a propósito, conduzem a ação, mas, devido à perspectiva em comum, podem ser consideradas uma conexão dentro da história.

Nessas circunstâncias, não se vê, na segunda cena em questão, o decote de Raimunda. Isso ilustra que Raimunda, com a morte de Paco, sai do seu papel de uma - objetificada dona de casa. A estrutura de poder foi, afinal, rompida, e a desgraça que sobreveio converte-se, então, numa oportunidade de experienciar um modo de vida alternativo. À medida que Almodóvar vai criando a narrativa, dá-se continuidade às críticas à estrutura do pensamento patriarcal, estabelecendo a posterior reestruturação desse pensamento.

Quando Paula entra na puberdade, ela também desperta o desejo de Paco, que é seu padrasto. O olhar de Paco — incorporado pelo movimento da câmera - percorre o corpo de Paula. Isso é visto não apenas quando ela, ingenuamente, senta-se em frente a ele com as pernas abertas, mas também quando ele a observa trocando de roupa em seu quarto. Quanto à roupa de Paula, a propósito, é possível perceber, nas primeiras cenas, que ela está vestida principalmente de rosa ${ }^{6}$, que é uma cor que está associada à feminilidade ${ }^{7}$.

Isso reflete os preceitos sociais que exigem que a mulher se posicione como mulher, enquanto o homem não precisa se posicionar como homem a fim de se definir. As duas categorias - homem e mulher - aparentam exercer papeis simétricos, porque o mundo foi e, provavelmente, sempre será dividido em metade por homens e metade por mulheres.

\footnotetext{
algo. Só na concepção do para-si é que há a possibilidade de existência, pois constituirá a essência pensada construída intencionalmente. Nesta, a condição humana está em aberto para o mundo, se abre para dar sentido e não é, portanto, definível (BEAUVOIR, 2005; SARTRE, 1988)." (LOURENÇO; MENDONÇA, 2018, p. 538).

6 "As características gerais que são atribuídas ao rosa são tipicamente femininas. A cor rosa simboliza a força dos fracos, como o charme e a amabilidade." (HELLER, 2013, p. 213).

${ }^{7} \mathrm{O}$ agrupamento de regras imposto ao feminino, com o propósito de circunscrever o ser mulher, chama-se "feminilidade", a qual carrega a ideia de que há coisas que são próprias de mulher, enquanto outras não. "Todo ser humano do sexo feminino não é, portanto, necessariamente mulher; cumpre-lhe participar dessa realidade misteriosa e ameaçada que é a feminilidade. Será esta secretada pelos ovários? Ou estará congelada no fundo de um céu platônico? E bastará uma saia fru-fru para fazê-la descer à Terra?" (BEAUVOIR, 2016a, p. 9-10).
} 
Beauvoir observa, todavia, que a categoria masculina é positiva e neutra, enquanto a feminina é negativa. O princípio masculino é a referência, é o tipo humano absoluto, enquanto todo o resto é julgado e diferenciado em relação a ele. A autora de $O$ segundo sexo afirma que "a humanidade é masculina, e o homem define a mulher não em si, mas relativamente a ele" (BEAUVOIR, 2016a, p. 12).

Partindo desse contexto, na trama almodovariana, Paco, em razão de seu desemprego, percebe reduzido seu poder como patriarca, porquanto é Raimunda quem agora assegura a renda familiar: "Certos homens temem a concorrência feminina" (BEAUVOIR, 2016a, p. 21). Deduzse, por conseguinte, que ele quer compensar sua impotência tentando impor seu poder físico sobre Raimunda, primeiramente, e depois - frustrado com a rejeição e com a nova perda de poder - sobre Paula. Nesse sentido, Beauvoir observa que "a violência cometida contra outrem é a afirmação mais evidente da alteridade desse outrem" (BEAUVOIR, 2016a, p. 109).

Estando bêbado, na cena de sua morte, Paco assedia Paula, na cozinha, de forma insistente. Ele tenta justificar o assédio, alegando não ser o pai de Paula e, portanto, isso lhe daria permissão, o que pode ser comprovado na fala de Paula à sua mãe: "Ele me disse que não era meu pai [...] desabotoou a calça, dizendo sempre que isso não era errado." (VOLVER, 2006, 17 min. 58 seg., tradução nossa) ${ }^{8}$. Ressalte-se também que Paco não leva a sério as ameaças de Paula, porque não a vê capaz de opor-se — psicologicamente e fisicamente — frente à sua "superioridade".

Apesar de Almodóvar não confrontar o público com as imagens da tentativa de violação sexual e do homicídio não planejado, a violência não se converte em tabu, ou seja, Almodóvar está preocupado com as consequências da violência e não com a violência em si mesma ${ }^{9}$ e, à vista disso, tampouco está preocupado com seus juízos de valor.

\footnotetext{
8 "Él me dijo que no era mi padre [...] Se desabrochó el pantalón, diciendo siempre que aquello no era malo."

${ }^{9}$ Pode-se apontar essa mesma intenção do cineasta em outro momento da obra: embora o pai de Raimunda só apareça nas conversas entre Raimunda, Irene e Sole, ele também tem um papel importante. Chega-se a saber que, em várias ocasiões, ele enganou Irene com a mãe de Agustina, bem como estuprou Raimunda, deixando-a grávida de Paula. O abuso sexual, no entanto, não é visualizado, por exemplo, com uma retrospectiva, porquanto Almodóvar, mais uma vez, enfatiza as consequências da violência em detrimento da violência em si mesma. Os espectadores, desse modo, não sabem do ocorrido até o momento da conversa final entre Raimunda e sua mãe Irene, na qual esclarecem todas as conexões. Portanto, é apenas no final que se pode entender que a história quase se repetiu e que a relação de Raimunda com seu pai deixou um trauma que é superado ao longo do filme. Por isso, "o casamento moderno só se compreende à luz do passado que ele perpetua" (BEAUVOIR, 2016b, p. 186). Almodóvar retrata, em Volver, uma reação feminina a essa estrutura opressora do patriarcado, a fim de descontinuá-la.
} 


\section{CINEMA LOGOPÁTICO: AS QUESTÕES FEMININAS EMERGEM ATRAVÉS DO CONCEITO-IMAGEM}

Quando Paula explica à Raimunda que Paco afirmou não ser seu pai e tentou abusá-la, levando-a a matá-lo com uma faca que estava na cozinha, a câmera converte-se no olhar de Raimunda, e Paula, então, fala diretamente com a câmera. Essa técnica usada por Almodóvar envolve o espectador na história e convida a audiência a visualizar Paco abrindo o zíper de suas calças e tentando atacar e estuprar a jovem garota.

Embora seja uma imagem perturbadora, ela transporta o espectador para o mundo feminino que Almodóvar está retratando e, dessa forma, uma noção de entendimento é criada, embora um ato violento de assassinato tenha sido cometido. Essa noção de entendimento é reproduzida por Raimunda quando ela diz a Paula: "Paula, lembre-se de que fui eu quem o matou, e que você não viu nada porque estava na rua. É muito importante que você se lembre disso." (VOLVER, 2006, 19 min.14 seg., tradução nossa) ${ }^{10}$.

Esse destaque dado a questões que são caras às mulheres forja uma atmosfera favorável às pautas feministas, desenvolvendo uma sintonia entre o mundo feminino e o espectador. Isso ocorre graças à dinâmica criada pelo que Cabrera chama de cinema logopático, isto é, problematiza-se "a racionalidade puramente lógica (logos) com a qual o filósofo encarava habitualmente o mundo, para fazer intervir também, no processo de compreensão da realidade, um elemento afetivo (ou 'pático')" (CABRERA, 2006, p. 16).

Essa dinâmica, portanto, fornece, ao presente texto, embasamento para aliar as teorias de Beauvoir ao trabalho de Almodóvar, mais especificamente ao filme Volver. Embora não haja, necessariamente, um vínculo conceitual entre este longa-metragem e $O$ segundo sexo, confrontar as duas obras torna possível interpretar, de maneira mais profícua, a situação da mulher e os meios de superá-la. Isso porque "o emocional não desaloja o racional: redefine-o" (CABRERA, 2006, p. 18). Ainda no tocante a essa relação entre cinema e filosofia, Ana Lucilia Rodrigues (2008, p. 65) afirma que "o filme é tomado como objeto da linguagem, como um lugar de representação, como momento de narração e como uma unidade comunicativa, enfim, o filme é como um texto".

Nesse sentido, ao assumir a autoria do assassinato, Raimunda sacrifica-se por sua filha; ela está completamente disposta a enfrentar as consequências de ter assassinado Paco, ainda

\footnotetext{
10 "Paula, recuerda que fui yo quien lo mató, y que tú no lo viste porque estabas en la calle. Es muy importante que recuerdes eso."
} 
que tenha sido Paula quem cometeu o crime. Esse é um exemplo que, adequadamente, ilustra as teses de Molly Haskell (1999, p. 24, tradução nossa), crítica e autora de cinema feminista, a qual, em seu mais influente trabalho - The woman's film —, argumenta: "os temas que envolvem as mulheres no cinema podem ser reduzidos a quatro categorias, na maioria das vezes sobrepostos ou combinados: sacrifício, aflição, escolha, competição." ${ }^{11}$ Certamente, o tema do sacrifício é determinante nessa cena em que Raimunda fala à Paula para dizer que foi ela, Raimunda, quem matou Paco. "Para Raimunda, o mais importante é salvar a filha." (STRAUSS, 2008, p. 311).

Seu comportamento não reflete nenhuma culpa. Ela não é questionada sobre suas ações ou chamada a confessar seu crime. O filme não deixa rastros (ou pistas) para imaginar que a protagonista poderia ter feito outra escolha. As mulheres de Volver não aceitam passivamente a violência que lhes é imposta. Matam se necessário. É importante lembrar que o filme não reflete sobre a ética dos acontecimentos, já que não é esse o seu propósito.

Mostrar o ato de violência de maneira explícita não teria, realmente, trazido o efeito desejado; isto é, Almodóvar quer, em vez disso, pôr em relevo as consequências psicológicas da violência, que é um dos temas centrais de Volver. Isso ele alcança deixando que Paula conte o ocorrido - por meio de um monólogo - enquanto suas reações, seu choro e sua tristeza são filmados em primeiro plano.

O primeiro plano, aliás, serve, por um lado, para deixar claras as emoções das personagens, pois as expõe a uma distância íntima que denota confidência; e, por outro, provoca emoções nos espectadores. Sobre a força do primeiro plano, Almodóvar argumenta:

\begin{abstract}
Percebi a força do primeiro plano, uma imagem bastante simples, mas cujo conteúdo narrativo é muito específico e de utilização muito complexa. O primeiro plano é uma radiografia da personagem e não permite enganos. [...] num primeiro plano se põe a nu a personagem e o ator, e também nos desnudamos. Fala-se com o coração. Não se trata apenas de dominar a técnica, mas de compreender seu significado. (ALMODÓVAR, 2008, p. 57).
\end{abstract}

Cria-se, então, uma atmosfera comovente, potencializada pelo primeiro plano e ainda mais intensificada pela música de fundo. Em outros termos, essa experiência - a partir das teorias de Cabrera - seria provocada pelo pathos (afetividade) e teria, em igual proporção, um valor cognitivo complementar. Sendo assim, embora o cinema não seja, de forma intrínseca,

\footnotetext{
11 “the themes of the woman's film can themselves be reduced to four categories, often found overlapping or in combination: sacrifice, affliction, choice, competition."
} 
filosofia, ele pode suscitar problematizações filosóficas a partir de uma experiência (não empírica, todavia).

Portanto, a noção de conceito-imagem, forjada por Cabrera, não é uma referência externa a alguma coisa, já que ela demanda a vivência de uma experiência que consolidará sua linguagem de configuração. Segundo ele, o conceito-imagem busca provocar "um impacto emocional que, ao mesmo tempo, diga algo a respeito do mundo, do ser humano, da natureza etc. e que tenha um valor cognitivo, persuasivo e argumentativo através de seu componente emocional" (CABRERA, 2006, p. 21).

Isso prova a importância do cinema almodovariano e, mais especificamente, em Volver, ao mostrar a violência estrutural à qual as mulheres estão submetidas. A relevância dessa abordagem, aliás, está não apenas ao escancarar as assimetrias entre homens e mulheres, mas, sobretudo, ao remodelar todos esses padrões, a fim de mostrar que um novo mundo é possível.

E é justamente por meio da emoção do cinema, servindo-se de artifícios imagéticos que incitam uma identificação dos espectadores com as personagens - fazendo com que riam e chorem com elas —, que Almodóvar gera reflexões em torno da situação das mulheres, a mesma já exposta por Beauvoir em $O$ segundo sexo. Ele traz à luz, também, os meios de as mulheres superarem as dificuldades que lhes são impostas pelo mundo dos homens, os desafios de superarem sua situação e afirmarem-se como sujeitos.

Cabe ressaltar, além disso, que a cozinha, que foi o palco da tentativa de violação sexual e do assassinato de Paco, tem muita importância nessa conjuntura. Isso porque a cozinha representa, alegoricamente, o mundo das mulheres, uma vez que — na sociedade patriarcal a maioria de suas tarefas (preparar comida, lavar, limpar) tem lugar nesse compartimento da casa. Logo, Paco, ao penetrar nesse mundo, cruza uma fronteira espacial e moral. A cozinha, como símbolo de repressão, converte-se, finalmente, na libertação definitiva do patriarca.

Como sugere Beauvoir, a mulher é precisamente o resultado de uma cultura machista, sendo erigida e erigindo a si própria como a figura projetada por uma aspiração masculina reificante. Sem vivenciar qualquer coisa que possa assemelhar-se com o humano, a mulher percebe-se enclausurada em uma pseudoessência deveras apropriada para a manutenção dos privilégios masculinos sobre si. Traiçoeiramente, essa essencialização da mulher também favorece a conservação de suas próprias "regalias" na qualidade de vítima. Como afirma Beauvoir (2016a, p. 14): 
Nenhum sujeito se define imediata e espontaneamente como o inessencial; não é o Outro que se definindo como Outro define o Um; ele é posto como Outro pelo Um definindo-se como Um. Mas para que o Outro não se transforme no Um é preciso que se sujeite a esse ponto de vista alheio.

A alteridade, contudo, é um importante conceito que se refere ao que é o Outro, ao que é externo a um "eu". Logo, a alteridade é a condição de Outro aos olhos do Um. Por esse ângulo, percebe-se a relevância da noção de alteridade como objeto — de construir o Outro — para a própria constituição de si mesmo como Sujeito. De acordo com Beauvoir, "a alteridade é uma categoria fundamental do pensamento humano. Nenhuma coletividade se define nunca como Uma sem colocar imediatamente a Outra diante de si” (BEAUVOIR, 2016a, p. 13).

Portanto, a própria natureza da consciência humana é intersubjetiva: o ser humano é uma espécie social, e é por meio do Outro que se alcança uma compreensão e uma certeza de si mesmo. Contudo, essa intersubjetividade pode tomar forma de distintos modos. Utilizando o termo heideggeriano Mitsein ${ }^{12}$, que significa ser-com-os-outros (no mundo), Beauvoir observa que o relacionamento pode ser de comunhão e reciprocidade (uma troca entre iguais) ou de conflito. Sustenta, porém, que as relações humanas, a princípio, inclinam-se para o conflito, como acontece nas relações entre homens e mulheres, em Volver.

\section{A MULHER COMO PAUSA CONTEMPLATIVA DO OLHAR MASCULINO}

Examinando mais a fundo a dinâmica da relação entre as personagens Paco, Raimunda e Paula, é possível perceber outras nuances: Paco é apresentado por Almodóvar como um "machista" bastante estereotipado. Os papéis de gênero são claramente examinados na cena em que Raimunda chega em casa e imediatamente começa a preparar o jantar. Antes que ela tenha sequer tempo de desempacotar suas coisas, ela já está dentro dos limites da cozinha (um ambiente feminino, segundo o discurso falocêntrico), enquanto Paco está recostado no sofá, em frente à televisão, bebendo cerveja.

\footnotetext{
${ }^{12} \mathrm{O}$ termo Mitsein (ou ser-com) foi introduzido pelo filósofo alemão Martin Heidegger, na filosofia, e surge em $O$ segundo sexo no sentido de sermos indivíduos separados e dependermos de uma coletividade à qual pertencemos, sempre imediatamente em relação aos outros. Homens e mulheres sempre foram Mitsein, não dois grupos distintos e separados que apareceram e se confrontaram ao longo da história, como a burguesia e o proletariado. Beauvoir acrescenta que é fora deste Mitsein que a oposição entre homens e mulheres tomou forma. Como muitos outros, na Paris da década de 1940, Beauvoir considerou possível combinar Heidegger com seu conceito de Mitsein, e Hegel, com sua dialética senhor-escravo. Desse modo, em $O$ segundo sexo, Beauvoir pressupõe que as relações humanas possam ser caracterizadas por conflitos e opressões ou por amizade e solidariedade. É a segunda forma que ela vê como mais autêntica, quando o ser humano está em sua "verdade" (GOTHLIN, 2003, p. 45-65).
} 
Na sequência, Paula senta-se no sofá ao lado de Paco. A partir daí, Almodóvar, fornece ao público um plano reverso, quando a câmera captura o olhar masculino — fetichista e objetificante $^{13}$ — de Paco e, em seguida, a câmera corta para um close da região da virilha de Paula. E. Ann Kaplan ${ }^{14}$, uma das fundadoras da abordagem feminista na crítica cinematográfica, argumenta que a mulher, no cinema, é "designada ao lugar de objeto (ausência), ela é depositária do desejo masculino, aparecendo de modo passivo e não ativo" (KAPLAN, 1995, p. 47).

Assim, Paula está claramente sujeita ao olhar e ao desejo de $\mathrm{Paco}^{15}$. O plano reverso, outrossim, coloca o espectador numa posição bastante aflitiva, tendo em vista que o público acredita que Paco seja o pai de Paula, embora mais tarde descubra-se que ele é o padrasto. Logo, explana Ismail Xavier que existem dois tipos de olhares do espectador, isto é:

O do espectador, em contato escopofílico ${ }^{16}$ direto com a forma feminina exposta para a sua apreciação (e conotando a fantasia masculina), e o do espectador fascinado com a imagem do seu semelhante colocado num espaço natural, ilusório, personagem através de quem ele ganha o controle e a posse da mulher na diegese. (XAVIER, 1983, p. 446).

Desse modo, constata-se que Almodóvar utiliza a mesma técnica que coisifica o corpo feminino, utilizada no cinema comercial. Contudo, o truque utilizado pelo Diretor é, a partir do recurso do plano reverso, transformar a câmera no olhar de Paco, que representa o olhar do

\footnotetext{
${ }^{13}$ Ismail Xavier, teórico e professor de cinema, explica que, para Laura Mulvey, "a mulher é objeto, seja de uma contemplação fetichista, seja de uma dissecação sádico-voyeurista que a toma como ser carente e culpado" (XAVIER, 1983, p. 368).

${ }^{14}$ É de bom tom ressaltar que tanto E. Ann Kaplan, como Laura Mulvey, teóricas feministas do âmbito cinematográfico, trabalham suas ideias em torno da psicanálise, tomando como base noções como a do complexo de castração nos homens. Por isso, cabe também dizer que o objetivo, ao mobilizar suas teorias, é o de abarcar pontos de vista diversos sobre uma mesma questão, a fim de gerar uma interlocução frutífera com Almodóvar e Beauvoir. Sabe-se, contudo, que Beauvoir apresenta ressalvas quanto à psicanálise, em $O$ segundo sexo, inclusive quanto ao complexo de castração, em especial no que concerne às mulheres, por, segundo ela, Freud tê-la "calcado sobre um modelo masculino" (BEAUVOIR, 2016a, p. 70). Esse determinismo freudiano rechaça a noção de escolha; mostra-se, dessa forma, incompatível com o conceito de liberdade existencialista, já que "falar de liberdade seria recusar a possibilidade de explicar tão perturbadoras concordâncias. Mas a ideia de liberdade não é compatível com a existência de certas constantes" (BEAUVOIR, 2016a, p. 75-76). Por outro lado, Beauvoir admite os progressos trazidos pela psicanálise, não pretendendo criticar esse sistema "em seu conjunto, mas tão somente examinar sua contribuição ao estudo da mulher." Nesse sentido, um dos objetivos, ao causar essa tensão entre autoras que enxergam a psicanálise de forma distinta, é mostrar que elas também apresentam pontos em comum quanto à situação da mulher e ao poder que o patriarcado exerce sobre elas, chegando a conclusões, na maioria das vezes, complementares, mesmo que por métodos distintos.

${ }^{15}$ É importante frisar que Paula - assim como as outras personagens femininas do filme - é colocada nessa posição de passividade apenas no começo da obra. Após essa parte inicial, ocorre uma ruptura com esse lugarcomum.

${ }^{16}$ Mulvey (1983, p. 440) defende que "o cinema oferece um número de prazeres possíveis. Um deles é a escopofilia. Há circunstâncias nas quais o próprio ato de olhar já é uma fonte de prazer”.
} 
patriarcado, causando angústia (pathos) no espectador, porquanto se trata de uma ação incestuosa, que fere a moral $(\log o s)$. Numa crítica codificada, Almodóvar, então, frustra a escopofilia que tentou ser gerada sobre o corpo da mulher e problematiza questões que envolvem a objetificação feminina, explorando o conceito-imagem do cinema por meio da autocensura do espectador.

Entretanto, os tons incestuosos — amoldados na fragmentação do corpo de Paula — ficam ainda mais evidentes, já que ela está com as pernas bem abertas, quase como se Paco as estivesse vendo como abertas à sua penetração. Pilar Aguilar, escritora e crítica feminista de cinema, argumenta, então, que "pouco importa a pessoa em seu conceito global — que, claro, inclui também seu corpo; um corpo é o que importa, ou certas partes de um corpo, como pedaços de carne apetitosos, sem a entidade globalizante" (AGUILAR, 1998, p. 116, tradução nossa). ${ }^{17}$

Percebe-se, portanto, que o olhar masculino que fragmenta e objetifica a mulher, no cinema comercial, é o mesmo olhar que o escritor francês Henry Montherlant põe sobre as mulheres, conforme pode ser verificado a partir da análise detida que faz Beauvoir de uma de suas personagens femininas:

É um escândalo odioso uma existência autônoma encerrada na carne de mulher; a carne feminina é detestável a partir do momento em que uma consciência a habita. $\mathrm{O}$ que convém à mulher é ser puramente carne; Montherlant aprova a atitude oriental: como objeto de gozo o sexo frágil tem um lugar na terra, humilde sem dúvida, mas válido; ele encontra uma justificação no prazer que o macho extrai desse objeto. (BEAUVOIR, 2016a, p. 273).

Tendo isso em vista, constata-se que os valores patriarcais estão enraizados em qualquer manifestação humana, sem exclusão das artes em geral. É esse o mundo que recebe a mulher desde que é concebida, um mundo que lhe prescreve uma essência rígida a qual se inscreve em seu corpo aculturado.

Inclusive, a ideia de os fragmentos do corpo de Paula e de Raimunda, na condição de não sujeitos, serem pedaços de carne apetitosos evoca um claro senso da dicotomia ativo/masculino e passivo/feminino que, como sugere Mulvey (1983, p. 444), existe no cinema dominante. Por isso, Paula, em seu estado passivo como mulher, parece não ter poder sobre o olhar fetichista de Paco, representado pelo close-up da virilha de Paula, sugerindo que seus

\footnotetext{
17 "No interesa la persona en su concepto global — que, por supuesto, incluye también su cuerpo; interesa un
} cuerpo, o ciertas partes de un cuerpo considerados como trozos de carne apetitosas, sin la entidad globalizadora." 
pensamentos são movidos por seu desejo masculino ativo de ter Paula, de penetrá-la e torná-la conquistada.

\section{O OUTRO ABSOLUTO SEM RECIPROCIDADE}

É preciso investigar o que é o Outro e o que é o Sujeito. A alteridade (ou outridade) "é tão original quanto a própria consciência" (BEAUVOIR, 2016a, p. 13) e constitui um alicerce de como os seres humanos apropriam-se do mundo e o entendem. Beauvoir constata que, ao longo da história, as civilizações fizeram uso de alteridades e dualidades (Dia/Noite, Sol/Lua, Bem/Mal), e que um indivíduo, ou grupo de indivíduos, nunca se posicionará (como Sujeito) sem simultaneamente posicionar o Outro.

A mulher carrega, por conseguinte, essa outridade, considerada um mistério inquietante, incurso na mitologia do Outro Absoluto. "Para que toda reciprocidade se apresente como impossível, é preciso que o Outro seja para si um outro, que sua subjetividade mesma seja afetada pela alteridade.” (BEAUVOIR, 2016a, p. 335).

É, aliás, nessa ambivalência que a mulher mantém um status divino, que é mais que humano, ao mesmo tempo em que mantém um que é menos que humano, menos racional. Assim, ela demarca os limites normativos do que é bom, santo, apropriado e aceitável daquilo que é mau, profano e perverso. A mulher ocupa, então, o lugar mais assustador para o homem: a fronteira que pode atrapalhar sua ordem, suas regras e leis sociais normativas.

Tendo isso em conta, Almodóvar desafia as convenções do cinema dominante, ao explorar o voyeurismo não apenas em seu estado puro, mas em um sentido de incesto fetichista que, indiscutivelmente, leva o instinto escopofílico a outro nível. Kaplan (1995, p. 53) expõe ainda mais esse argumento teórico ao apresentar a ideia de que "voyeurismo e fetichismo são mecanismos que o cinema dominante usa para construir o espectador masculino de acordo com as necessidades de seu inconsciente".

Desse modo, quando Paula prepara-se para dormir, há uma leve fenda, pois sua porta está entreaberta. Através dela, surge a silhueta de Paco, o qual voyeuristicamente espreita. Essa cena não apenas está de acordo com a teoria de Mulvey, a qual desenvolve o conceito de escopofilia, como também assume uma forma ainda mais forte, pois, neste caso em particular, Paula não sabe que está sendo observada, dando a Paco, como ativo/masculino, uma sensação ainda maior de poder por meio da qual ele projeta suas fantasias sobre a garota. "O olhar 
masculino determinante projeta sua fantasia na figura feminina, estilizada de acordo com essa fantasia” (MULVEY, 1983, p. 444).

A feminista Mary Ann Doane, teórica e crítica de cinema, salienta o sentido de proibição ao observar que "o desejo do espectador, na teoria do cinema contemporâneo, é em geral delineado como voyeurismo ou fetichismo [...] em relação ao corpo feminino. A imagem orquestra um olhar, um limite e sua transgressão prazerosa" (DOANE, 2000, p. 497, tradução nossa). ${ }^{18} \mathrm{O}$ público fica a par do olhar de Paco para o corpo proibido de Paula, enquanto seus longos cabelos e seu corpo nu são vistos diretamente em frente da silhueta de Paco. Como Paco é o sujeito do olhar, Paula torna-se "a imagem, o objeto para o qual se está olhando" (AGUILAR, 1998, p. 113). ${ }^{19}$

A fragmentação é, então, novamente repetida, tendo como alvo o corpo de Raimunda ${ }^{20}$ lavando louça na cozinha. Nessa cena, Almodóvar volta a apresentar ao espectador uma personagem feminina em um lugar da casa tido como "lugar de mulher." A insistência de Almodóvar de que é Paco quem usa os pratos põe em destaque ainda mais a ideia de segregação de gênero no âmbito doméstico. Para homens, como Paco, lavar a louça é uma obrigação doméstica da mulher (outras tarefas de limpeza, consideradas femininas, também são mostradas no filme).

\section{CONCLUSÃO}

Uma das principais características do cinema de Almodóvar é a sua relação íntima com o universo feminino. E, em Volver, ele desenvolve uma forte crítica à objetificação do olhar masculino no cinema, seja ele do diretor, do ator ou do próprio espectador. O cineasta espanhol demonstra, assim, que a mulher tem sido representada, no cinema comercial (ou tradicional),

\footnotetext{
18 "spectatorial desire, in contemporary film theory, is generally delineated as either voyeurism or fetishism [...] The imagem orchestrates a gaze, a limit, and its pleasurable transgression".

19 "la imagen, el objeto mirado".

20 "De um diretor heterossexual, devaneios como esses seriam evidências para a reclamação feminista de que os filmes são uma invenção desprezível do voyeurismo masculino. Mas o que um homem gay vê nos seios e nádegas de uma mulher? Mexendo no rímel de (Penélope) Cruz e fazendo escolhas meticulosas sobre os cardigans que usava, Almodóvar é como um menino brincando com uma boneca. 'Não, não', ele retaliou. 'O papel é sobre sua humanidade, seu coração e também seu rosto. Garotas bonitas geralmente não conseguem esses papéis. Nos Estados Unidos, eles não sabem como usar atrizes. Eu a salvei de Hollywood" (STOKES, 2006, tradução nossa). ["From a heterosexual director, reveries like these would be evidence for the feminist complaint that movies are a sleazy contrivance of male voyeurism. But what does a gay man see in a woman's boobs and buttocks? Fussing over Cruz's mascara and making finicky choices about the cardigans she wore, Almodovar is like a little boy playing with a doll. 'No, no,' he retaliated. 'The role is about her humanity, her heart as well as her face. Pretty girls don't usually get such parts. In America, they don't know how to use actresses. I saved her from Hollywood”].
} 
como mera condição imagética, com o intuito de satisfazer o olhar fetichista e objetificante do homem.

Por outro lado, em sua descrição — passo a passo — da situação da mulher, Beauvoir mostra como as mulheres são forçadas a abrir mão de seu direito existencial à transcendência e aceitar uma prisão circunscrita e repetitiva. Não há escapatória para elas, exceto por meio do homem. Isto é, o homem tem projetos, atividades, realizações; a mulher só tem o homem.

Por isso, deve-se ter em mente que, para Beauvoir, a inferioridade da mulher, na sociedade, não é resultado de diferenças naturais, mas de diferenças na educação do homem e da mulher. A dominação masculina não é, portanto, inerente ou predestinada, mas condicionada em todos os estágios de desenvolvimento. Isto é, o homem “aprende” seu poder.

Da mesma maneira, a mulher não nasce medíocre, passiva ou imanente. Ao invés disso, ela é socializada de modo a acreditar que mulheres adequadas devem incorporar tais características. Logo, sutilmente (ou não), através de mitos que lhe condicionam uma essência, ela é levada a acreditar que negar seu verdadeiro eu é a única maneira de alcançar a felicidade e obter aceitação.

Em Volver, Almodóvar, conquanto retrate a mulher como Outro, também provoca uma reação das personagens femininas à opressão que sofrem. Nesse antagonismo mútuo, entre homens e mulheres, estas saem da imanência que as confina em seu sexo e começam a também enxergar o homem como Outro, numa relação de reciprocidade. Dessa forma, a mulher não mais seria a representante intrêmula da alteridade, encarcerada em um pedaço de carne; de modo diverso, ela se torna ao mesmo tempo Sujeito e Objeto, em relação ao homem.

É por esse ângulo que Beauvoir denuncia que cada vida humana deve permitir a interação das duas forças: imanência e transcendência. Ao longo da história, porém, o homem negou à mulher o papel transcendente. Logo, a análise do feminismo, em Almodóvar, torna-se profícua nessa interlocução com os conceitos beauvoirianos constantes em $O$ segundo sexo.

Isso se dá com o auxílio da noção de logopatia, defendida por Cabrera, porquanto o estímulo ao pathos do espectador promove a reflexão em torno de temas caros às pautas feministas. E é por essa razão que o estudo realizado, neste texto, tem relevância, porque o filme, conceitualmente, traz à luz o processo de outrificação da mulher. Contudo, o cinema almodovariano não apenas realiza uma metáfora dessa outrificação, como também assume um papel de combate, no qual a mulher também objetifica o homem, criando uma relação de reciprocidade, que é o ideal buscado por Beauvoir em $O$ segundo sexo. 


\section{REFERÊNCIAS}

AGUILAR, Pilar. Mujer, Amor y Sexo en el Cine Español de los 90. Madrid: Editorial Fundamentos, 1998.

ALMODÓVAR, Pedro. O cinema como ambição. [Entrevista concedida a] Frédéric Strauss. Conversas com Almodóvar; tradução Sandra Monteiro e João de Freire; tradução de "Na esteira do tempo" e filmografia de Volver, André Telles. Rio de Janeiro: Zahar, 2008, p. 57.

BEAUVOIR, Simone. O segundo sexo: a experiência vivida. 3. ed. Tradução de Sérgio Milliet. Rio de Janeiro: Nova Fronteira, 2016b. v. 2

BEAUVOIR, Simone. O segundo sexo: fatos e mitos. 3. ed. Tradução de Sérgio Milliet. Rio de Janeiro: Nova Fronteira, 2016a.

CABRERA, Julio. O cinema pensa: uma introdução à filosofia através dos filmes. Tradução de Ryta Vinagre. Rio de Janeiro: Rocco, 2006.

DOANE, Mary Ann. Film and Masquerade: theorizing the female spectator. In: STAM, R; MILLER, T (ed.). Film and theory: an anthology. Malden, Mass: Blackwell, 2000.

FEMENÍAS, María Luisa. A crítica de Judith Butler a Simone de Beauvoir. Sapere Aude, Belo Horizonte, v. 3, n. 6, p. 310-339, 2012. Disponível em: http://periodicos.pucminas.br/index.php/SapereAude/article/view/4619. Acesso em: 06 out. 2020.

GOTHLIN, Eva. Reading Simone de Beauvoir with Martin Heidegger. In: CARD, Claudia (org.). The Cambridge Companion to Simone de Beauvoir. Cambridge: University Press, 2003, p. 45-65.

HASKELL, Molly. The woman's film. In: THORNHAM, Sue (ed.). Feminist film theory: a reader. Edinburgh: EUP, 1999.

HELLER, Eva. A psicologia das cores: como as cores afetam a emoção e a razão. Tradução de Maria Lúcia Lopes da Silva. São Paulo: Gustavo Gili, 2013.

KAPLAN, E. Ann. A mulher e o cinema: os dois lados da câmera. Tradução de Hellen Marcia Potter Pessoa. Rio de Janeiro: Rocco, 1995.

KRUKS, Sonia. Simone de Beauvoir: teaching Sartre about freedom. In: SIMONS, Margaret A. Feminist interpretations of Simone de Beauvoir. University Park, PA, Pennsylvania State University Press, 1995.

LOURENÇO, Silmara Silveira; MENDONÇA, Viviane Melo de. A fenomenologia existencial em Paulo Freire: possíveis diálogos. Revista Filosofia e Educação, Campinas, v. 10, n. 3, p. 530-547, set./dez. 2018. Disponível em:

https://periodicos.sbu.unicamp.br/ojs/index.php/rfe/article/view/8653268. Acesso em: 04 set. 2020. 
MULVEY, Laura. Prazer visual e cinema narrativo. In: XAVIER, Ismail (org.). A experiência do cinema: antologia. Rio de Janeiro: Graal, 1983.

REYNOLDS, Jack. Existencialismo. 2. ed. Tradução de Caesar Souza.Petrópolis, RJ: Vozes, 2014. (Série Pensamento Moderno).

RODRIGUES, Ana Lucilia. Pedro Almodóvar e a feminilidade. São Paulo: Escuta, 2008.

SARTRE, Jean-Paul. O existencialismo é um humanismo; apresentação e notas Arlette Elkaïm-Sartre. Tradução de João Batista Kreuch. 4. ed. Petrópolis, RJ: Vozes, 2014. (Vozes de bolso).

STOKES, Emily. Sex was my way of coping with death'. The observer. Reino Unido, 13 ago. 2006. Film. Disponível em:

https://www.theguardian.com/film/2006/aug/13/features.review1. Acesso em: 2 out. 2020.

STRAUSS, Frédéric. Conversas com Almodóvar. Tradução de Sandra Monteiro e João de Freire; tradução de "Na esteira do tempo" e filmografia de Volver, André Telles. Rio de Janeiro: Zahar, 2008.

VOLVER. Direção: Pedro Almodóvar. Produção: Esther García/Agustín Almodóvar. Espanha: Sony Pictures Classics, 2006, 1 DVD, NTSC, son., color.

XAVIER, Ismail (org.). A experiência do cinema: antologia. Rio de Janeiro: Graal, 1983. 